\title{
Perbandingan metode Double Exponential Smoothing dan Simple Moving Average pada kasus peramalan penjualan
}

\section{Comparison of the Double Exponential Smoothing method and the Simple Moving Average in the case of sales forecasting}

\author{
Fajar Rohman Hari a, Waskita Sari b, Chamdan Mashuri c,* \\ a,b Teknik Informatika, Universitas Islam Negeri Maulana Malik Ibrahim Malang, Malang, Indonesia \\ c Sistem Informasi, Universitas Hasyim Asy'ari Tebuireng Jombang, Jombang, Indonesia \\ email:afajar@ti.uin-malang.ac.id, c,* chamdanmashuri@unhasy.ac.id
}

*Koresponden

I N F O A R T I K E L

Sejarah artikel:

Menerima 9 Maret 2021

Revisi 5 April 2021

Diterima 18 April 2021

Online 27 Agustus 2021

\section{Kata kunci:}

algoritma peramalan double exponential smoothing forecasting perbandingan algoritma simple moving average

Keywords:

algorithm comparisons double exponential smoothing forecasting

forecasting algorithm simple moving average

Style APA dalam menyitasi artikel ini:

Hari, F. R., Sari, W., \& Mashuri, C. (2021)

Perbandingan metode Double Exponential Smoothing dan Simple Moving Average pada kasus peramalan penjualan. Teknologi: Jurnal Ilmiah Sistem Informasi, 11(2), 93100.

\begin{abstract}
ABSTRAK
Toko Bangunan Barokah (TB. Barokah) yang berada di Singosari, Malang, Jawa Timur adalah salah satu toko yang menjual bahan bangunan. Beberapa barang yang dijual adalah semen putih dan semen hitam. Jumlah penjualan semen setiap bulan sangat beragam dan fluktuatif. Semen hitam menempati angka sangat tinggi dibandingkan semen hitam pada grafik penjualan setiap bulannya. Begitu juga dengan semen hitam merek Bosowa, semen putih merek Gresik dan merek Tiga Roda meskipun permintaan kecil, tetapi masih terjadi pergerakan jumlah penjualannya. Jumlah permintaan yang sangat fluktuatif menjadikan jumlah persediaan produk yang disiapkan tidak pasti, yang dipengaruhi oleh jumlah jenis dan merek, sehingga manajemen persediaan produk kesulitan dalam penyediaannya. Penelitian ini bertujuan untuk meramal jumlah semen yang terjual di bulan berikutnya, serta untuk mengetahui kinerja antara kedua metode Double Exponential Smoothing (DES) dan Simple Moving Average (SMA) untuk melakukan forecasting hasil penjualan semen pada TB. Barokah. Metode SMA mampu melakukan peramalan dengan data permintaan atau penjualan yang stabil/konstan. Sedangkan metode DES mampu dan dapat memberikan nilai pada bobot secara bertingkat dengan data up to date. DES mampu melakukan peramalan penjualan semen tiap bulan dengan nilai rata-rata percentange error (PE) 0,14\%, sedangkan SMA dengan nilai rata-rata PE 1,35\%. Berdasarkan hasil pengujian menggunakan data dari TB. Barokah didapatkan bahwa metode yang paling efektif adalah DES karena memiliki nilai PE lebih kecil dibandingkan dengan SMA.
\end{abstract}

\section{ABSTRACT}

Barokah Building Shop (TB. Barokah) located in Singosari, Malang, East Java is one of the shops that sells building materials. Some of the items being sold are white cement and black cement. The number of cement sales every month is very diverse and fluctuating. Black cement occupies a very high number compared to black cement on the sales chart every month. Likewise with the black cement from the Bosowa brand, white cement from the Gresik brand and the Tiga Roda brand, although demand is small, there is still a movement in the number of sales. The fluctuating amount of demand made the amount of product inventory prepared uncertain, which was influenced by the number of types and brands, so that the product inventory management had difficulty in supplying it. This study aims to predict the amount of cement sold in the following month, as well as to determine the performance between the two double exponential smoothing (DES) methods and the simple moving average (SMA) to forecast cement sales results in TB. Barokah. The SMA method is able and can perform forecasts with stable/constant demand or sales data. Meanwhile, the DES method is able and can provide values to the stratified weights 
with up to date data. DES is capable of forecasting cement sales each month with an average percentange error (PE) of $0.14 \%$, while the $S M A$ is with an average PE value of $1.35 \%$. Based on the test results using data from TB. Barokah found that the most effective method is DES because it has a smaller PE value than the SMA.

Teknologi: Jurnal IImiah Sistem Informasi dengan lisensi CC BY NC SA.

\section{Pendahuluan}

Semen memiliki jenis yang beragam. Beberapa merek dan jenis dari semen portland tidak mengakibatkan pencemaran, diantaranya semen putih, karena semen putih tidak terdapat Kalsium Oksida $(\mathrm{CaO})$ (Satyarno, 2004). Namun, semen yang sering digunakan oleh masyarakat adalah semen hitam. Toko Bangunan Barokah yang berada di Singosari, Malang, Jawa Timur yang selanjutnya akan disebut sebagai TB. Barokah. TB. Barokah merupakan salah satu toko yang menjual semen dengan jenis semen putih dan semen hitam. Jumlah permintaan semen putih dan semen hitam setiap bulan sangat beragam dan fluktuatif. Semen hitam menempati angka sangat tinggi pada grafik penjualan setiap bulannya dan jumlah permintaannya fluktuatif. Begitu juga dengan jenis semen yang lain, seperti semen hitam merek Bosowa, semen putih merek Gresik, dan semen putih merek Tiga Roda. Meskipun ketiga jenis semen tersebut permintaannya kecil, tetapi masih ada peminatnya. Jumlah permintaan yang fluktuatif menjadikan jumlah persediaan produk yang disiapkan tidak pasti. Hal itu dipengaruhi oleh jumlah jenis dan merek, sehingga pihak manajemen persediaan produk kesulitan dalam penyediaannya. Kondisi tersebut menimbulkan beberapa permasalahan, diantaranya adalah: 1) Jumlah persediaan yang tidak dapat memenuhi jumlah permintaan berdampak pada pengadaan produk yang memerlukan waktu lama, sehingga membuat pelanggan tidak puas dengan pelayanannya; 2) Jumlah penumpukan produk yang jumlah permintaannya rendah, hal tersebut akan berdampak pada kualitas semen itu sendiri; dan 3) Tingginya biaya penyimpanan.

Sakkung dan Sinuraya (2011) pada penelitiannya menyatakan bahwa metode Economic Order Quantity (EOQ) mampu menentukan besar stok yang sama dengan kebutuhan perusahaan. Akan tetapi, metode EOQ merupakan metode klasik yang menempatkan supplier menjadi rekan bisnis. Sementara itu, karena paradigma laba dan rugi diterapkan oleh perusahaan. Sehingga penggunaan model ini menyebabkan berganti-ganti supplier. Hal tersebut dapat mengganggu proses produksi akibat relasi perusahaan dengan supplier yang tidak berdasar pada hubungan kerja sama yang erat.

Darnila, Asrianda, dan Jannah (2019) dalam penelitiannya menerapkan metode Double Exponential Smoothing (DES) untuk memprediksi jumlah orang membuat paspor di kantor Imigrasi Kelas II Kota Lhokseumawe. Hasil penelitian Darnila, Asrianda, dan Jannah (2019) prediksi berhasil dilakukan dan mendapatkan nilai MAPE (Mean Absolute Percentage Error) sebesar 5,5856.

Putra dan Solikin (2019) dalam penelitiannya menyarankan untuk menerapkan metode Simple Moving Average (SMA) dalam memprediksi penjualan/permintaan serta persediaan kebutuhan Alat Tulis Kantor (ATK) di Kota Palembang. Hasil dari penelitian Putra dan Solikin (2019) dalam menerapkan SMA untuk memprediksi persediaan pada bulan berikutnya dengan data historis yang telah dilakukan melibatkan data tiga bulan sebelumnya didapatkan MAPE sebesar 5,241. Menurut Putra dan Solikin (2019), metode SMA tepat diterapkan pada data konstan terhadap variasi dan sederhana untuk diterapkan. Data paenjualan semen pada TB. Barokah merupakan pola data horizontal, terjadi saat data observasi berfluktuasi di sekitaran suatu nilai konstan atau rata nilai tengah membentuk garis horizontal dapat disebut juga dengan data stasioner (Andini \& Auristandi, 2016).

Pengambilan dan penerapan metode DES dan SMA dilakukan dengan beberapa dasar, diantaranya menelaah dari hasil penelitian terdahulu terkait kelebihan dan kekurangan dari kedua metode tersebut. Metode SMA mampu dan dapat melakukan perhitungan dengan data permintaan/penjualan yang stabil dan/atau konstan. Metode DES mampu dan dapat memberikan nilai bobot secara bertingkat dengan data yang up to date.

Berdasarkan permasalahan tersebut, pada penelitian ini diusulkan agar TB. Barokah menerapkan sebuah metode dan sistem perencanaan untuk prediksi permintaan semen di periode berikutnya. Harapannya agar di masa mendatang TB. Barokah mampu menyediakan produk dengan jumlah yang wajar sehingga tidak terjadi penumpukan persediaan di gudang. penelitian ini memberikan saran agar mengukur atau menghitung jumlah permintaan semen disetiap bulan dengan menerapkan metode DES. Metode ini mampu memproses data yang relatif lebih sedikit karena metode DES melakukan dua 
kali proses smoothing, akan tetapi metode DES memerlukan pengecekan secara bertahap dan secara continou dengan melakukan proses pengecekan ulang terhadap data yang telah dimasukkan apakah sudah valid atau masih ada error. Selain itu penelitian ini juga melakukan perbandingan untuk mengetahui prediksi data permintaan penjualan semen yang akurat dan optimum antara metode SMA dengan DES. Hasil dari perbandingan kedua metode tersebut diukur dengan MAPE.

\section{State of the Art}

Apriliani, Zainuddin, Agussalim, dan Hasanuddin (2020) dalam penelitiannya menerapkan metode SMA guna melihat jumlah permintaan menu yang paling diminati di masa mendatang. Harapan dari hasil penelitian tersebut dapat membantu manajemen persediaan menu di sebuah rumah makan dalam mengambil keputusan berupa rekomendasi. Data yang digunakan dalam penelitian ini adalah data transaksi dari jenis permintaan selama 15 bulan. Data latih yang digunakan sejumlah 10.515 data pada kurun waktu bulan Januari-Desember 2018. Data uji yang digunakan sejumlah 2.246 data pada kurun waktu bulan Januari-Maret 2019. Hasil pengujian dalam melakukan peramalan bulanan untuk Top-10 menu menghasilkan nilai MAPE sebesar $4 \%$ yang memiliki arti kinerja algoritma sangat baik. Sedangkan pengujian hasil ramalan harian menghasilkan nilai MAPE yang cukup tinggi yaitu sebesar $39,2 \%$ yang memiliki arti kinerja algoritma kurang bagus.

Ariyanto, Puspitasari, dan Ericawati (2017) dalam penelitiannya menerapkan metode DES dengan tujuan melakukan peramalan ketersediaan pangan yang menjadi kebutuhan pokok seperti padi, jagung, kedelai, dan ubi kayu, ubi jalar, kacang tanah dan kacang hijau. Jumlah produksi pangan yang tidak menentu menjadi suatu masalah bagi Badan Ketahanan Pangan (BKP) Provinsi Jawa Timur dalam menentukan kebijakan mendatang. Guna mengatasi permasalahan tersebut, maka diperlukan suatu solusi yaitu dengan menerapkan peramalan produksi tanaman pangan di periode mendatang berdasarkan tahun dengan menggunakan data masa lalu. Peramalan diterapkan dengan menggunakan DES Holt. Pada penelitian ini, peramalan menggunakan data komoditas padi dengan range waktu sebanyak 22 periode berdasarkan tahun. Data tahun 1993-2014 untuk ramalan 2015 menghasilkan nilai parameter alpha $=0,46$ dan beta $=0,26$, sehingga parameter mempengaruhi nilai PE. Nilai PE yang dihasilkan pada penelitian ini cenderung memiliki nilai PE yang kecil yaitu 2,22\%.

Andini dan Auristandi (2016) dalam penelitiannya melakukan peramalan jumlah stok alat tulis kantor di UD. Achmad Jaya dengan menerapkan metode DES dengan tujuan agar tidak terjadi penumpukan stok di gudang. Data historis yang dihitung menggunakan metode DES adalah jumlah data penjualan ATK di tahun 2014 pada bulan Januari-Desember. Pengujian peramalan dilakukan dengan cara perhitungan PE dan MAPE. MAPE dengan alpha 0,7 bernilai 12,36 dan peramalan 408,63 pack. MAPE terkecil antara alpha 0,1-0,9 maka akan digunakan sebagai peramalan.

Rachman (2018) dalam penelitiannya menerapkan Moving Average dan Exponential Smoothing pada perusahaan tekstil guna melakukan prediksi jumlah produksi dengan mengacu pada data time series masa lampau. Guna mendapatkan kinerja algoritma yang bagus, Rachman (2018) mengungkapkan bahwa data yang diperlukan cukup besar dan bersifat tren. Hasil dari penelitian ini adalah kinerja Exponential Smoothing lebih baik dari pada Moving Average.

Agusta dan Anwar (2019) dalam penelitiannya menerapkan Single Exponential Smoothing dalam meramal penjualan lensa kacamata pada periode di masa mendatang. Hasil pengujian pada penelitian tersebut mendapatkan nilai Mean Absolute Error (MAE) terbaik sebesar 44,14 dengan nilai $\alpha=0,9$, di bandingkan ketika menggunakan nilai $\alpha \leq 0,9$.

Penerapan metode SMA untuk peramalan penjualan mainan anak, akan sangat membantu pemilik toko jika dilakukan peramalan dalam membeli barang untuk stok, sehingga stok tidak akan menumpuk banyak. Metode peramalan yang digunakan adalah SMA dengan mengambil data penjualan puzzle jeruk pada bulan Januari 2018 hingga bulan Juni 2019 yang merupakan berpola stasioner, terjadi dari pergerakan hasil penjulan yang naik turun yang membentuk garis lurus atau horizontal. Pengolahan data historis menggunakan metode SMA, menghitung error dari hasil prediksi menggunakan metode Mean Absolute Deviation (MAD), Mean Square Error (MSE) dan MAPE, hasil akhir diperoleh setelah melalui proses perhitungan prediksi dan perhitungan error. Hasil dari penelitian ini didapatkan nilai pergerakan 9 yang memiliki akurasi yang baik (tingkat kesalahan terkecil) yaitu MAD sebesar 4,23457, MAPE sebesar 4,2638 dan MSE 30,166 dengan hasil peramalan 96 pcs penjualan puzzle jeruk di bulan Juli 2019 (Astuti, Novianti, Hidayat, \& Maulina, 2019). 


\section{Metode Penelitian}

Metode penelitian ini diilustrasikan melalui Gambar 1 yang terdiri dari pengumpulan data, mengembangkan sistem dengan menerapkan algoritma DES dan SMA, melakukan pengujian, dan evaluasi hasil pengujian.

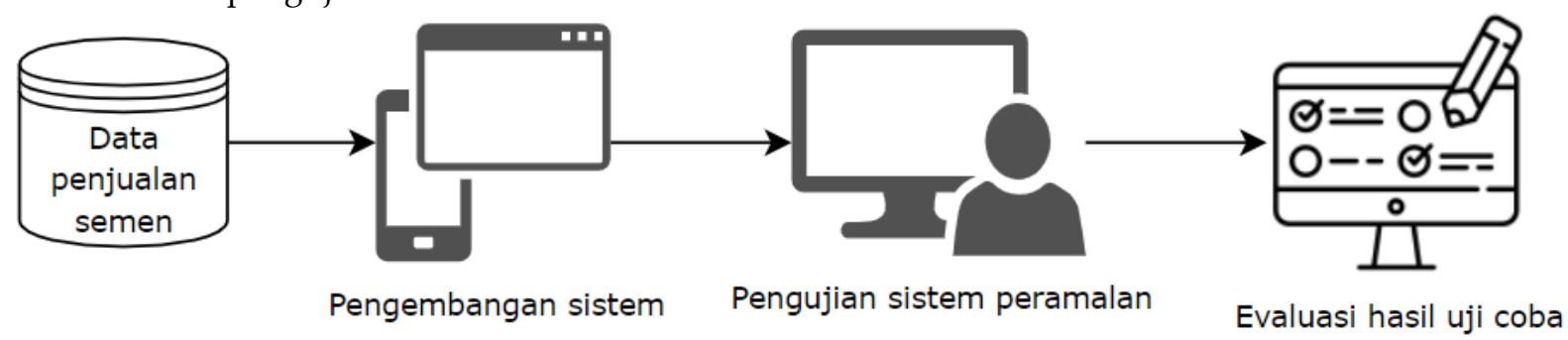

Gambar 1. Metode penelitian

\subsection{Pengumpulan Data}

Data pada penelitian ini diperoleh dengan cara mengumpulkan data secara primer pada TB. Barokah. Data yang diperoleh berupa data time series hasil penjualan semen hitam dan semen putih merek Gresik dan merek Tiga Roda. Data yang digunakan yaitu data time series hasil penjualan bulanan dari tahun 2018-2020. Semua data diambil dengan satuan kilogram $(\mathrm{kg})$. Beberapa data disajikan pada Tabel 1.

\begin{tabular}{ccccc}
\multicolumn{2}{c}{ Tabel 1. Data permintaan semen tahun $2018-2019$} \\
\hline \multirow{2}{*}{ Periode } & \multicolumn{2}{c}{ Semen Putih } & \multicolumn{2}{c}{ Semen Hitam } \\
\cline { 2 - 5 } & Gresik & Tiga Roda & Gresik & Bosowa \\
\hline 1 & 2.000 & 4.000 & 40.800 & 16.000 \\
2 & 2.000 & 4.000 & 49.040 & 23.800 \\
3 & 3.960 & 8.480 & 78.480 & 25.520 \\
4 & 2.200 & 4.400 & 40.880 & 15.400 \\
5 & 1.920 & 3.840 & 40.200 & 15.600 \\
6 & 1.840 & 4.080 & 42.000 & 16.600 \\
7 & 2.200 & 3.920 & 44.480 & 16.800 \\
8 & 1.840 & 4.800 & 39.800 & 14.800 \\
9 & 2.440 & 5.200 & 44.000 & 16.800 \\
10 & 1.680 & 3.680 & 41.000 & 15.120 \\
11 & 1.920 & 4.520 & 49.200 & 14.280 \\
12 & 1.840 & 3.440 & 48.000 & 15.200 \\
13 & 2.000 & 4.000 & 78.480 & 16.000 \\
14 & 3.960 & 4.000 & 40.800 & 25.520 \\
15 & 2.000 & 8.480 & 49.040 & 23.800 \\
16 & 2.200 & 3.840 & 42.000 & 15.600 \\
17 & 1.920 & 4.400 & 40.200 & 15.400 \\
18 & 1.840 & 4.080 & 40.880 & 16.600 \\
19 & 1.840 & 5.200 & 44.000 & 16.800 \\
20 & 2.200 & 4.800 & 44.480 & 14.800 \\
21 & 2.440 & 3.920 & 39.800 & 16.800 \\
22 & 1.920 & 3.440 & 48.000 & 15.120 \\
23 & 1.680 & 3.680 & 49.200 & 14.280 \\
24 & 1.840 & 4.520 & 41.000 & 15.200 \\
\hline & & & &
\end{tabular}

\subsection{Pengembangan Sistem}

Pengembangan sistem pada penelitian ini dengan menerapkan kombinasi algoritma peramalan berbasis statistik yaitu SMA dan DES guna meramal jumlah permintaan semen.

Flowchart algoritma DES ditunjukkan pada Gambar 2, dengan langkah sebagai berikut (Suliyanto, 2008):

1). Menentukan besarnya nilai dari pemulusan exponential pertama yang diberi simbol $S^{\prime} t$ dengan Persamaan 1,

$\mathrm{S}_{\mathrm{t}}^{\prime}=\alpha \times \mathrm{X}_{\mathrm{t}}+(1-\alpha) \mathrm{S}_{\mathrm{t}-1}^{\prime}$

2). Menentukan besarnya nilai dari pemulusan exponential kedua yang diberi simbol ( $\left(\mathrm{S}^{\prime \prime} \mathrm{t}\right)$ dengan Persamaan 2, 


$$
S_{t}{ }_{t}=\alpha \times X_{t}+(1-\alpha) S^{\prime \prime}{ }_{t-1}
$$

3). Menentukan besarnya nilai konstanta dari pengurangan antara pemulusan exponential kedua dengan exponential pertama yang diberi simbol $\alpha$ t dengan Persamaan 3, $\alpha_{\mathrm{t}}=2 \mathrm{~S}_{\mathrm{t}}^{\prime}-\mathrm{S}_{\mathrm{t}}^{\prime \prime}$

4). Menentukan besarnya nilai slope (bt) dengan Persamaan 4, dan

$$
b_{t}=\frac{\alpha}{1-\alpha}\left(S^{\prime}{ }_{t}-S^{\prime \prime}{ }_{t}\right)
$$

5). Menentukan besarnya nilai peramalan dengan Persamaan 5 ,

$$
F_{t+m}=\alpha_{t}+b_{t}(\mathrm{~m})
$$

di mana $S^{\prime}{ }_{t}$ merupakan nilai pemulusan exponential pertama, $\alpha$ merupakan parameter pemulusan exponential yang besarnya $0<\alpha<1, S_{t-1}^{\prime}$ merupakan nilai pemulusan exponential sebelumnya, $X_{t}$ merupakan nilai riil peridoe $t, S^{\prime \prime}{ }_{t}=$ nilai pemulusan exponential kedua, $\alpha_{t}$ merupakan besarannya kosntanta periode $t, b_{t}$ merupakan Slope/nilai tren dari data yang sesuai, $F_{t+m}$ merupakan nilai peramalan untuk periode ke depan, dan $m$ merupakan selang waktu peramalan.

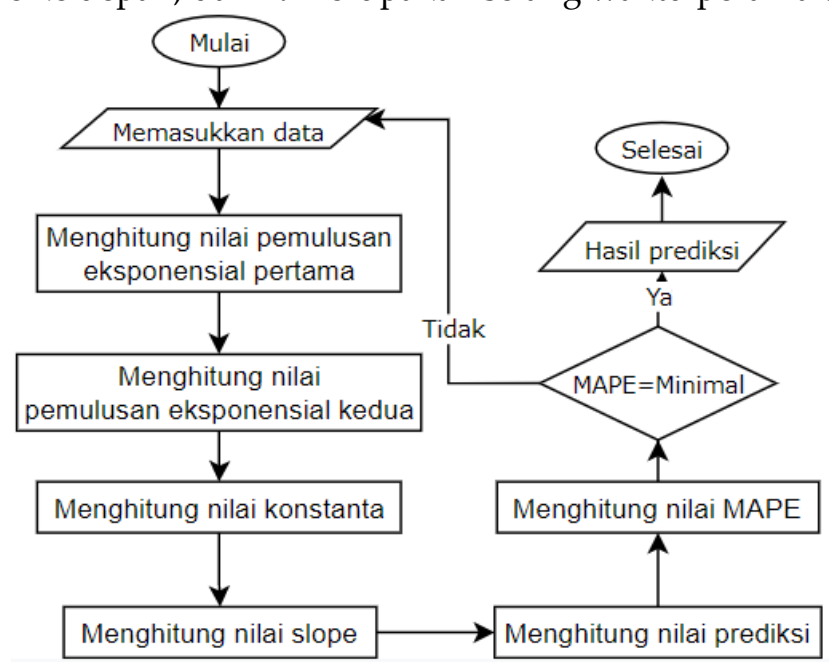

Gambar 2. Flowchart algoritma DES

Flowchart algoritma SMA ditunjukkan pada Gambar 3, dengan Persamaan 6 dan Persamaan 7 (Rahmad, 2018), di mana $F_{t+1}$ adalah peramalan untuk periode $t+1$ mendatang, $x$ merupakan permintaan untuk periode $t$, sedangkan $t$ merupakan orde yang digunakan.

$F_{t+1}=\frac{x_{1}+x_{2}+\cdots x_{y}}{t_{1}+t_{2}+\cdots t_{y}}$

$F_{t+1}=\frac{\sum_{i=1}^{t} x_{1}}{\sum_{i=1}^{t} i}$

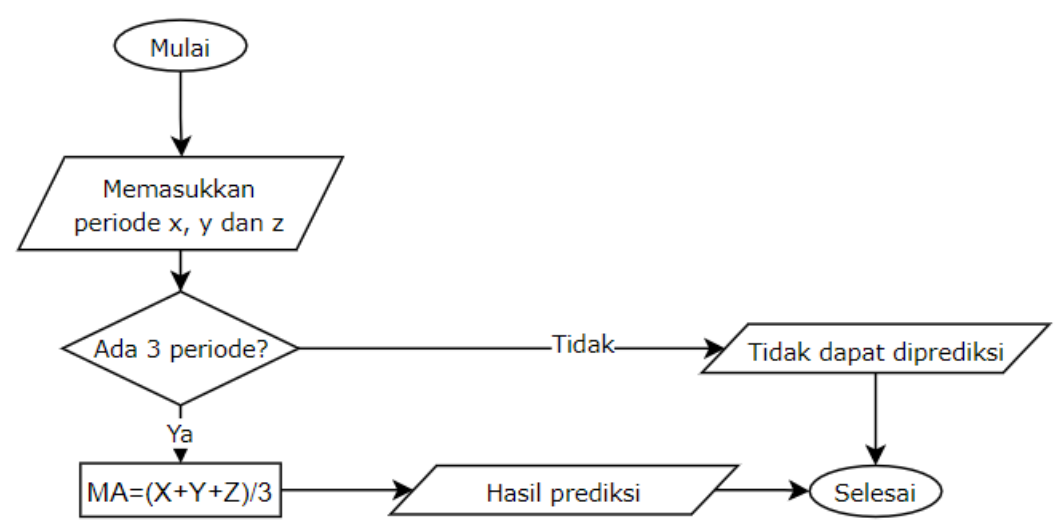

Gambar 3. Flowchart algoritma SMA

\subsection{Pengujian Sistem Peramalan}

Pada tahapan ini dilakukan uji coba dari data yang sudah dikumpulkan dengan menggunakan kedua algoritma antara DES dan SMA. Data latih yang digunakan yaitu data time series hasil penjualan bulanan dari tahun 2018-2019. Sedangkan data uji yang digunakan adalah bulan Januari-Maret 2020.

\subsection{Evaluasi Hasil Uji Coba}

Hasil dari uji coba dilakukan evaluasi menggunakan MAPE. 


\section{Hasil dan Pembahasan}

\subsection{Double Exponential Smoothing (DES)}

Tabel 2 adalah hasil prediksi yang didapatkan dari data permintaan semen (Dt) di masa lalu, perhitungan smoothing pertama $\left(S^{\prime} t\right)$, smoothing kedua $\left(S^{\prime \prime} t\right)$, konstanta $(a)$, dan nilai slope/tren $(b t)$ yang akhirnya diperoleh hasil prediksi $(F t)$ di masa mendatang pada bulan Januari-Maret 2020 yang ditunjukkan pada periode 25, 26, dan 27.

Tabel 2. Peramalan metode DES pada semen putih Gresik

\begin{tabular}{|c|c|c|c|c|c|c|}
\hline \multirow[t]{2}{*}{ Periode } & $\begin{array}{c}\text { Permintaan } \\
\text { Gresik }\end{array}$ & SES & DES & $\begin{array}{c}\text { Nilai } \\
\text { Kosntanta }\end{array}$ & Nilai Slope/Trend & Prediksi \\
\hline & $D t$ & $S^{\prime} t$ & $S^{\prime \prime} t$ & $a$ & $b_{t}$ & $\mathrm{Ft}$ \\
\hline 1 & 2.000 & $2.000,00$ & $2.000,00$ & $2.000,00$ & 0,00 & \\
\hline 2 & 2.000 & $2.000,00$ & $1.800,00$ & $2.200,00$ & 35,29 & $2.000,00$ \\
\hline 3 & 3.960 & $2.294,00$ & $1.694,10$ & $2.893,90$ & 105,86 & $2.235,29$ \\
\hline 4 & 2.200 & $2.279,90$ & $1.612,56$ & $2.947,24$ & 117,77 & $2.999,76$ \\
\hline 5 & 1.920 & $2.225,92$ & $1.543,31$ & $2.908,52$ & 120,46 & $3.065,01$ \\
\hline 6 & 1.840 & $2.168,03$ & $1.482,68$ & $2.853,37$ & 120,94 & $3.028,98$ \\
\hline 7 & 2.200 & $2.172,82$ & $1.437,94$ & $2.907,71$ & 129,69 & $2.974,31$ \\
\hline 8 & 1.840 & $2.122,90$ & $1.396,89$ & $2.848,91$ & 128,12 & $3.037,40$ \\
\hline 9 & 2.440 & $2.170,47$ & $1.373,24$ & $2.967,69$ & 140,69 & $2.977,03$ \\
\hline 10 & 1.680 & $2.096,90$ & $1.344,46$ & $2.849,33$ & 132,78 & $3.108,38$ \\
\hline 11 & 1.920 & $2.070,36$ & $1.318,90$ & $2.821,82$ & 132,61 & $2.982,11$ \\
\hline 12 & 1.840 & $2.035,81$ & $1.294,55$ & $2.777,07$ & 130,81 & $2.954,43$ \\
\hline 13 & 2.000 & $2.030,44$ & $1.275,47$ & $2.785,40$ & 133,23 & $2.907,88$ \\
\hline 14 & 3.960 & $2.319,87$ & $1.304,59$ & $3.335,15$ & 179,17 & $2.918,63$ \\
\hline 15 & 2.000 & $2.271,89$ & $1.319,22$ & $3.224,56$ & 168,12 & $3.514,32$ \\
\hline 16 & 2.200 & $2.261,11$ & $1.328,58$ & $3.193,63$ & 164,56 & $3.392,67$ \\
\hline 17 & 1.920 & $2.209,94$ & $1.327,93$ & $3.091,95$ & 155,65 & $3.358,19$ \\
\hline 18 & 1.840 & $2.154,45$ & $1.319,11$ & $2.989,78$ & 147,41 & $3.247,60$ \\
\hline 19 & 1.840 & $2.107,28$ & $1.305,43$ & $2.909,14$ & 141,50 & $3.137,20$ \\
\hline 20 & 2.200 & $2.121,19$ & $1.297,25$ & $2.945,13$ & 145,40 & $3.050,64$ \\
\hline 21 & 2.440 & $2.169,01$ & $1.298,29$ & $3.039,73$ & 153,66 & $3.090,53$ \\
\hline 22 & 1.920 & $2.131,66$ & $1.293,47$ & $2.969,85$ & 147,92 & $3.193,39$ \\
\hline 23 & 1.680 & $2.063,91$ & $1.279,69$ & $2.848,14$ & 138,39 & $3.117,77$ \\
\hline 24 & 1.840 & $2.030,32$ & $1.264,31$ & $2.796,34$ & 135,18 & $2.986,53$ \\
\hline 25 & & $2.001,78$ & $1.252,78$ & $2.750,77$ & 132,18 & $2.931,51$ \\
\hline 26 & & $1.977,51$ & $1.244,14$ & $2.710,88$ & 129,42 & $2.882,94$ \\
\hline 27 & & $1.956,88$ & $1.237,65$ & $2.676,11$ & 126,92 & $2.840,30$ \\
\hline
\end{tabular}

\subsection{Simple Moving Average (SMA)}

Tabel 3 memperlihatkan data dalam kurun 24 periode atau data selama dua tahun serta hasil prediksi permintaan semen putih merek Gresik (periode 25, periode 26, dan periode 27) yang telah menerapkan metode SMA selama tiga bulan pertama atau mengambil rata-rata tiga bulanan (3MA) yang diambil pada bulan Januari-Maret 2020 dengan hasil prediksi yaitu 1.813,33 kg, 1.844,44 kg, dan 1.888,89 kg, serta dilkukan uji akurasai prediksi dengan MAPE sehingga diperoleh nilai PE berturut turut yaitu $0,128,0,133$ dan 0,013 .

Tabel 4 memiliki arti bahwa hasil prediksi dengan menggunakan metode DES dan SMA pada periode 25, periode 26 dan periode 27 (Januari-Maret 2020) yaitu untuk metode DES secara berurutan mulai periode 1 adalah 1.943, 1.894 dan 1.852 serta untuk metode SMA berurutan mulai periode 1 adalah 1.813,33, 1.844,44 dan 1.888,89 dan pada tingkat setelah dilakukan perhitungan dengan MAPE yaitu untuk metode DES berurutan mulai periode 1 adalah 1,28, 1,08 dan 1,28 sedangkan untuk metode SMA berurutan mulai periode 1 adalah 1,47, 1,16, dan 1,22.

Dari hasil perbandingan kedua metode untuk prediksi tiga bulan mendatang dapat disimpulkan bahwa metode DES merupakan metode yang lebih baik dibandingkan dengan metode SMA karena memiliki nilai MAPE lebih kecil. Hal tersebut diperoleh berdasarkan dari hasil perbandingan 
peramalan menggunakan dua metode tersebut memiliki tingkat error yang berbeda-beda pada tiap bulan, artinya tidak setiap periode peramalan menghasilkan nilai error yang kecil, terlihat pada hasil PE terendah metode DES adalah 1,08\% dan hasil PE terendah metode SMA adalah 1,16\%.

Tabel 3. Prediksi metode SMA pada semen putih Gresik

\begin{tabular}{|c|c|c|}
\hline Periode & $\begin{array}{l}\text { Permintaan } \\
\text { Gresik }\end{array}$ & $3 \mathrm{MA} \mid \%$ Error $\mid$ \\
\hline 1 & 2.000 & \\
\hline 2 & 2.000 & \\
\hline 3 & 3.960 & \\
\hline 4 & 2.200 & $2.653,330,0036364$ \\
\hline 5 & 1.920 & $2.720,000,0739583$ \\
\hline 6 & 1.840 & $2.693,330,0043478$ \\
\hline 7 & 2.200 & $1.986,670,0418182$ \\
\hline 8 & 1.840 & $1.986,670,0315217$ \\
\hline 9 & 2.440 & $1.960,000,0172131$ \\
\hline 10 & 1.680 & $2.160,00 \quad 0,025$ \\
\hline 11 & 1.920 & $1.986,670,0609375$ \\
\hline 12 & 1.840 & $2.013,330,0451087$ \\
\hline 13 & 2.000 & $1.813,33 \quad 0,0085$ \\
\hline 14 & 3.960 & $1.920,000,0232323$ \\
\hline 15 & 2.000 & $2.600,00 \quad 0,121$ \\
\hline 16 & 2.200 & $2.653,330,0190909$ \\
\hline 17 & 1.920 & $2.720,000,0302083$ \\
\hline 18 & 1.840 & $2.040,000,0407609$ \\
\hline 19 & 1.840 & $1.986,670,0043478$ \\
\hline 20 & 2.200 & $1.866,670,2009091$ \\
\hline 21 & 2.440 & $1.960,000,0852459$ \\
\hline 22 & 1.920 & $2.160,000,1994792$ \\
\hline 23 & 1.680 & $2.186,670,3619048$ \\
\hline 24 & 1.840 & $2.013,330,1858696$ \\
\hline 25 & 2.013 & $1.813,330,1281457$ \\
\hline 26 & 1.813 & $1.844,440,1334559$ \\
\hline 27 & 1.844 & $1888,890,0135542$ \\
\hline
\end{tabular}

Tabel 4. Perbandingan hasil prediksi

\section{Kesimpulan}

\begin{tabular}{ccccccc}
\hline \multirow{2}{*}{ Periode } & \multicolumn{2}{c}{ Aktual } & \multicolumn{4}{c}{ Peramalan } \\
& SMA & DES & SMA & MAPE & DES & MAPE \\
\hline 1 & 2013 & 1920 & 1813,33 & 1,47 & 1943 & 1,28 \\
2 & 1813 & 1680 & 1844,44 & 1,16 & 1894 & 1,08 \\
3 & 1844 & 1840 & 1888,89 & 1,22 & 1852 & 1,28 \\
\hline
\end{tabular}

Dari hasil pengujian didapat nilai MAPE terhadap hasil peramalan menunjukan nilai yang cenderung naik turun terlihat pada tiga periode di bulan Januari-Maret metode DES menunjukan nilai paling akurat yaitu 1,08 dan metode SMA yaitu 1,16. Berdasarkan hasil pengujian, hasil perbandingan dari metode DES dan SMA dapat disimpulkan bahwa metode yang lebih baik kinerjanya adalah DES, karena memiliki nilai terkecil dibandingkan dengan SMA.

\section{Ucapan Terima Kasih}

Terimkasih untuk tim penelitian dan semua yang ikut membantu berjalannya penelitian secara lancar.

\section{Referensi}

Agusta, A., \& Anwar, S. N. (2019). Aplikasi Forecasting Penjualan dengan Metode Single Exponential Smoothing (Studi Kasus: Optik Nusantara). SINTAK 2019: Seminar Nasional Teknologi Informasi E Aplikasi Komputer 2019, 3, pp. 278-281.

Andini, T. D., \& Auristandi, P. (2016). Peramalan Jumlah Stok Alat Tulis Kantor di UDACHMAD JAYA Menggunakan Metode Double Exponential Smoothing. Jurnal Ilmiah Teknologi Informasi Asia, 10(1).

Apriliani, A., Zainuddin, H., Agussalim, A., \& Hasanuddin, Z. B. (2020). Peramalan Tren Penjualan Menu Restoran Menggunakan Metode Single Moving Average. Jurnal Teknologi Informasi dan Ilmu Komputer, 7(6), 1161-1168. 
Ariyanto, R., Puspitasari, D., \& Ericawati, F. (2017). Penerapan Metode Double Exponential Smoothing pada Peramalan Produksi Tanaman Pangan. JIP (Jurnal Informatika Polinema), 4(1), 57-62.

Astuti, Y., Novianti, B., Hidayat, T., \& Maulina, D. (2019). Penerapan Metode Single Moving Average untuk Peramalan Penjualan Mainan Anak. Seminar Nasional Sistem Informasi dan Teknik Informatika (SENSITIf 2019) (pp. 253-261). Makassar: STMIK Dipanegara Makassar dan STMIK Profesional Makassar.

Darnila, E., Asrianda, A., \& Jannah, R. (2019). Aplikasi Peramalan Jumlah Pemohon Paspor Menggunakan Metode Double Exponential Smoothing pada Kantor Imigrasi Kelas II Kota Lhokseumawe. TECHSI: Jurnal Penelitian Teknik Informatika, 11(2), 257-267.

Putra, M. S., \& Solikin, I. (2019). Aplikasi Peramalan Stok Alat Tulis Kantor (ATK) Menggunakan Metode Single Moving Average (SMA) pada PT. Sinar Kencana Multi Lestari. CESS (Journal of Computer Engineering, System and Science), 4(2).

Rachman, R. (2018). Penerapan Metode Moving Average dan Exponential Smoothing pada Peramalan Produksi Industri Garment. Jurnal Informatika, 5(1), 211-220.

Rahmad, B. (2018). Perbandingan Metode Peramalan pada Penjualan Gantungan Baju. Kediri: Universitas Nusantara PGRI Kediri 2018.

Sakkung, C. V., \& Sinuraya, C. (2011). Perbandingan Metode EOQ (Economic Order Quantity) dan JIT (Just in Time) Terhadap Efisiensi Biaya Persediaan dan Kinerja Non-Keuangan (Studi Kasus pada PT Indoto Tirta Mulia). Akurat: Jurnal Ilmiah Akuntansi, 2(5).

Satyarno, I. (2004). Penggunaan Semen Putih untuk Beton Styrofoam Ringan (BATAFOAM). Seminar Nasional Teknik Sipil (pp. 36-45). Yogyakarta: Universitas Gadjah Mada.

Suliyanto, S. (2008). Teknik Proyeksi Bisnis. Yogyakarta: Andi. 